\title{
Comparison of Oncotype DX and Mammostrat risk estimations and correlations with histologic tumor features in low-grade, estrogen receptor-positive invasive breast carcinomas
}

\author{
Geza Acs ${ }^{1,2,3}$, John Kiluk ${ }^{2}$, Loretta Loftus ${ }^{2}$ and Christine Laronga ${ }^{2}$ \\ ${ }^{1}$ Department of Anatomic Pathology, Comprehensive Breast Program, Moffitt Cancer Center, Tampa, FL, \\ USA $;^{2}$ Department of Women's Oncology, Comprehensive Breast Program, Moffitt Cancer Center, Tampa, FL, \\ USA and ${ }^{3}$ Women's Pathology Consultants, Ruffolo Hooper and Associates, Tampa, FL, USA
}

\begin{abstract}
Several molecular tests have been developed to estimate risk of distant recurrence and help clinical decision-making regarding adjuvant chemotherapy in patients with early stage breast carcinoma. Both Oncotype DX, a 21-gene expression profile, and Mammostrat, an immunohistochemistry-based assay, are validated to stratify patients into groups with low, intermediate and high risk of distant recurrence. However, they have not been compared head-to-head and little data are available regarding their correlation with clinicopathologic tumor features. In this study, we compared the clinicopathologic tumor features with risk estimations by Oncotype DX and Mammostrat in 106 low-grade estrogen receptor (ER)-positive breast carcinomas. Double immunohistochemical stain for pancytokeratin and Ki-67 was performed to assess cell proliferation in cancer vs stromal/inflammatory cells. Tumors showing intermediate/high risk by Oncotype DX, but not by Mammostrat, showed increased stromal cellularity, presence of inflammatory cells and increased proliferation in stromal/inflammatory cells. Discrepant cases showing intermediate/high risk by Oncotype DX but low risk by Mammostrat were associated with increased stromal cellularity, presence of inflammatory cells and increased proliferation in stromal/inflammatory cells, compared with concordant cases showing low risk by both assays. Our results suggest that low-grade ER-positive breast carcinomas with increased stromal/ inflammatory cell proliferation may show an apparent increased risk of distant recurrence as assessed by Oncotype DX, which uses RNA extracted from a mixture of tumor and stromal/inflammatory cells in the assay. Mammostrat, which examines cancer cells only, may provide a better estimation of likely tumor behavior in a subgroup of low-grade breast carcinomas.
\end{abstract}

Modern Pathology (2013) 26, 1451-1460; doi:10.1038/modpathol.2013.88; published online 7 June 2013

Keywords: breast cancer; Mammostrat; Oncotype DX; risk estimation

Breast cancer is a heterogeneous disease with a wide range of biological features and clinical behavior. ${ }^{1,2}$ Besides patient characteristics (ie, age and comorbidities), oncologists have traditionally relied on clinicopathologic tumor features (tumor size, histologic grade, lymph node, hormone receptor and HER2 status) to assess risk of

Correspondence: Dr G Acs, MD, PhD, Women's Pathology Consultants, Ruffolo Hooper and Associates, 5751 Hoover Blvd., Tampa, FL 33634, USA.

E-mail: geza.acs@moffitt.org

Received 31 January 2013; revised 8 March 2013; accepted 17 March 2013; published online 7 June 2013 recurrence and guide recommendations for adjuvant chemotherapy. However, such treatment decisions remain challenging, especially with estrogen receptor (ER)-positive early stage tumors where the absolute benefit of chemotherapy is difficult to perceive. ${ }^{3}$ Although the traditional clinicopathological prognostic/predictive factors show strong association with treatment response and patient outcome, concerns exist that they cannot adequately capture the diversity of clinical behaviors of breast cancer nor guide individualized treatment recommendations.

In recent years, based on gene expression profiling studies highlighting the marked heterogeneity of 
breast cancers and defining molecular subgroups of the disease, ${ }^{4,5}$ multiple molecular assays to identify signatures associated with prognosis ${ }^{6-8}$ and response to therapy ${ }^{9}$ were developed to help clinical decision-making regarding adjuvant chemotherapy. Currently, the most widely used such assay in the United States is Oncotype DX (Genomic Health, Redwood City, CA, USA), an RT-PCR based assay analyzing 16 cancer-related and 5 reference genes to provide a Recurrence Score. The Recurrence Score is based on expression levels of genes related to hormone receptor/HER2 signaling and cell proliferation to predict a 10-year distant recurrence risk as a continuous variable, assuming that patients receive adjuvant hormonal manipulation. It is also subdivided into three risk categories: low $(<18)$, intermediate (18-30) and high $(>30)$ scores.

The Mammostrat immunohistochemical assay (Clarient, Aliso Viejo, CA, USA), based on the assumption that gene expression can be translated into protein expression data, ${ }^{10}$ measures the expression of SLC7A5, involved in nutrient transport; p53, involved in cell cycle checkpoint control; HTF9C, a gene whose expression oscillates during the cell cycle; NDRG1, a stress- and hypoxiainducible gene; and CEACAM5, a carcinoembryonic differentiation antigen. ${ }^{10-12}$ Based on the expression of these proteins a Prognostic Index is calculated and patients are classified into three risk categories as well: low $(\leq 0)$, moderate ( $>0$ and $\leq 0.7$ ) and high $(>0.7)$ risk of recurrence.

Although both the Oncotype DX Recurrence Score $^{3,13,14}$ and the Mammostrat Prognostic Index ${ }^{10-12}$ have been validated in multiple studies, and the Recurrence Score has been incorporated into clinical guidelines for management of breast cancer, ${ }^{15,16}$ several questions remain unanswered. Although both were validated in the same cohorts of patients (NSABP B14 and B20), they have not been compared head-to-head and little data are available regarding their correlation with clinicopathologic tumor features. Although both tests were shown to predict outcome and response to therapy when analyzing large numbers of cases, their prognostic and predictive accuracy in a given individual case has not been adequately addressed and little has been done to study the possibility that some cases may have a falsely low- or high-risk prediction when compared with what would be expected based on clinicopathologic features and/or outcome. ${ }^{17}$ Furthermore, the reproducibility of the Oncotype DX assay, performed with tissue extracts without microdissection of cancer cells from the stroma, is not well established and several studies suggest that stromal and inflammatory cells can have a significant effect on the Recurrence Score. ${ }^{2,17-19}$ Indeed, we have recently shown that a proliferative, cellular stroma and inflammatory cells associated with tumor cells may account for unexpected intermediate-/high-risk estimations by Recurrence Score in low-grade breast carcinomas. ${ }^{19}$ In contrast, the immunohistochemistry
Table 1 Summary of clinicopathologic features

\begin{tabular}{|c|c|}
\hline & $\begin{array}{l}\text { All carcinomas } \\
\quad(\mathrm{n}=106)\end{array}$ \\
\hline Age (years, median, mean \pm s.e.m.) & $57.5(58.3 \pm 1.0)$ \\
\hline Tumor size (cm, median, mean \pm s.e.m.) & $1.2(1.4 \pm 0.1)$ \\
\hline \multicolumn{2}{|l|}{ Menopausal status (\%) } \\
\hline Premenopausal & $37(35)$ \\
\hline Postmenopausal & $69(65)$ \\
\hline \multicolumn{2}{|l|}{ Histologic type (\%) } \\
\hline Ductal (NST) & $72(67)$ \\
\hline Lobular & $4(4)$ \\
\hline Tubular & $22(21)$ \\
\hline Cribriform & $4(4)$ \\
\hline Mucinous & $4(4)$ \\
\hline \multicolumn{2}{|l|}{ Tubule formation (\%) } \\
\hline 1 & $30(28)$ \\
\hline 2 & $71(67)$ \\
\hline 3 & $5(5)$ \\
\hline \multicolumn{2}{|l|}{ Nuclear pleomorphism (\%) } \\
\hline 1 & $20(19)$ \\
\hline 2 & $85(80)$ \\
\hline 3 & $1(1)$ \\
\hline \multicolumn{2}{|l|}{ Mitotic activity (\%) } \\
\hline 1 & $106(100)$ \\
\hline 2 & $0(0)$ \\
\hline 3 & $0(0)$ \\
\hline $\begin{array}{l}\text { Number of mitoses per } 10 \mathrm{HPF} \\
\text { (median, mean } \pm \text { s.e.m.) }\end{array}$ & $1(1.8 \pm 0.2)$ \\
\hline \multicolumn{2}{|l|}{ Lymphatic invasion (\%) } \\
\hline Absent & $104(9)$ \\
\hline Present & $2(2)$ \\
\hline \multicolumn{2}{|l|}{$p N$ stage $(\%)$} \\
\hline $0(\mathrm{i}-)$ & $93(87)$ \\
\hline $0(\mathrm{i}+)$ & $5(5)$ \\
\hline $1 \mathrm{mi} / 1 \mathrm{a}$ & $8(8)$ \\
\hline $\begin{array}{l}\text { Percent ER reactivity } \\
\text { (median, mean } \pm \text { s.e.m.) }\end{array}$ & $100(95.1 \pm 0.8)$ \\
\hline ER H-score (median, mean \pm s.e.m.) & $295(276.8 \pm 3.3)$ \\
\hline $\begin{array}{l}\text { Percent PR reactivity } \\
\text { (median, mean } \pm \text { s.e.m.) }\end{array}$ & $85(75.6 \pm 2.7)$ \\
\hline PR H-score (median, mean \pm s.e.m.) & $222.5(203.0 \pm 8.7)$ \\
\hline \multicolumn{2}{|l|}{ HER2 status (\%) } \\
\hline Negative & $106(100)$ \\
\hline Positive & $0(0.0)$ \\
\hline \multicolumn{2}{|l|}{ Cellular stroma (\%) } \\
\hline Absent & $72(68)$ \\
\hline Present & $34(32)$ \\
\hline \multicolumn{2}{|l|}{ Inflammatory cells (\%) } \\
\hline Absent & $78(74)$ \\
\hline Present & $28(26)$ \\
\hline
\end{tabular}

Abbreviations: ER, estrogen receptor; HPF, high-power field; H-score, histologic score; NST, no special type; PR, progesterone receptor.

based Mammostrat assay examines only cancer cells and its results are not affected by the presence of inflammatory cells or the features of tumor stroma. 
Table 2 Correlation of clinicopathologic tumor features with Oncotype DX Recurrence Score and Mammostrat Prognostic Index in lowgrade, ER-positive invasive breast carcinomas

\begin{tabular}{|c|c|c|c|c|c|c|}
\hline & \multicolumn{3}{|c|}{ Oncotype DX Recurrence Score } & \multicolumn{3}{|c|}{ Mammostrat Prognostic Index } \\
\hline & $<18(\mathrm{n}=68)$ & $R S \geq 18(\mathrm{n}=38)$ & $\mathrm{P}$-value & $<0(\mathrm{n}=91)$ & $>0(\mathrm{n}=15)$ & $\mathrm{P}$-value \\
\hline Age (years, median, mean \pm s.e.m.) & $57.5(58.0 \pm 1.1)$ & $57.5(59.0 \pm 1.9)$ & $0.6372^{*}$ & $57(57.7 \pm 1.0)$ & $66(62.5 \pm 3.2)$ & $0.0934^{*}$ \\
\hline Tumor size (cm, median, mean \pm s.e.m.) & $1.3(1.4 \pm 0.1)$ & $1.2(1.3 \pm 0.1)$ & $0.2721^{*}$ & $1.2(1.3 \pm 0.1)$ & $1.5(1.5 \pm 0.2)$ & $0.1597 *$ \\
\hline \multicolumn{7}{|l|}{ Menopausal status (\%) } \\
\hline Premenopausal & $21(31)$ & $16(42)$ & $0.2905 * *$ & $32(35)$ & 5 (33) & $1.000^{* *}$ \\
\hline Postmenopausal & $47(69)$ & $22(58)$ & & $59(65)$ & $10(67)$ & \\
\hline \multicolumn{7}{|l|}{ Histologic type (\%) } \\
\hline Ductal (NST) & $46(67)$ & $26(68)$ & 0.2107 * & $61(67)$ & $11(7)$ & $0.6869 * *$ \\
\hline Lobular & $1(2)$ & $3(8)$ & & $4(4)$ & $0(0)$ & \\
\hline Other special type & $21(31)$ & $9(24)$ & & $26(29)$ & $4(27)$ & \\
\hline \multicolumn{7}{|l|}{ Tubule formation (\%) } \\
\hline 1 & $24(35)$ & $6(16)$ & $0.0191 * *$ & $27(30)$ & $3(20)$ & $0.4292^{* *}$ \\
\hline 2 & $43(63)$ & $28(74)$ & & $59(65)$ & $12(80)$ & \\
\hline 3 & $1(2)$ & $4(10)$ & & $5(5)$ & $0(0)$ & \\
\hline \multicolumn{7}{|l|}{ Nuclear pleomorphism (\%) } \\
\hline 1 & $12(18)$ & $8(21)$ & $0.6977 * *$ & $19(21)$ & $1(7)$ & $0.0231^{* *}$ \\
\hline 2 & $55(80)$ & $30(79)$ & & $72(79)$ & $13(87)$ & \\
\hline 3 & $1(2)$ & $0(0)$ & & $0(0)$ & $1(7)$ & \\
\hline \multicolumn{7}{|l|}{ Mitotic activity (\%) } \\
\hline 1 & $68(100)$ & $38(100)$ & NA & $91(100)$ & $15(100)$ & NA \\
\hline 2 & $0(0)$ & $0(0)$ & & $0(0)$ & $0(0)$ & \\
\hline 3 & $0(0)$ & $0(0)$ & & $0(0)$ & $0(0)$ & \\
\hline $\begin{array}{l}\text { Number of mitoses per } 10 \mathrm{HPF} \\
\text { (median, mean } \pm \text { s.e.m.) }\end{array}$ & $1(1.6 \pm 0.2)$ & $1(2.1 \pm 0.4)$ & $0.1444^{*}$ & $1(1.7 \pm 0.2)$ & $1(2.1 \pm 0.5)$ & $0.5180^{*}$ \\
\hline \multicolumn{7}{|l|}{ Lymphatic invasion (\%) } \\
\hline Absent & $66(97)$ & $38(100)$ & $0.5357^{* *}$ & $89(98)$ & $15(100)$ & $1.000 * *$ \\
\hline Present & $2(3)$ & $0(0)$ & & $2(2)$ & $0(0)$ & \\
\hline \multicolumn{7}{|l|}{$p N$ stage $(\%)$} \\
\hline $0(\mathrm{i}-)$ & $60(88)$ & $33(87)$ & $0.5358^{* *}$ & $79(87)$ & $14(93)$ & $0.4672^{* *}$ \\
\hline $0(\mathrm{i}+)$ & $4(6)$ & $1(3)$ & & $4(4)$ & $1(7)$ & \\
\hline $1 \mathrm{mi} / 1 \mathrm{a}$ & $4(6)$ & $4(10)$ & & $8(9)$ & $0(0)$ & \\
\hline ER H-score (median, mean \pm s.e.m.) & $300(278.8 \pm 4.1)$ & $285(273.3 \pm 5.6)$ & $0.3267^{*}$ & $300(277.9 \pm 3.5)$ & $290(270.3 \pm 10.3)$ & $0.6763^{*}$ \\
\hline PR H-score (median, mean \pm s.e.m.) & $235(218.1 \pm 9.7)$ & $200(175.8 \pm 16.3)$ & $0.0345^{*}$ & $220(201.1 \pm 9.7)$ & $240(225.3 \pm 17.4)$ & $0.5634^{*}$ \\
\hline \multicolumn{7}{|l|}{ Cellular stroma (\%) } \\
\hline Absent & $59(87)$ & $13(34)$ & $<0.0001^{* *}$ & $61(67)$ & $11(7)$ & $0.7699^{* *}$ \\
\hline Present & $9(13)$ & $25(66)$ & & $30(33)$ & $4(27)$ & \\
\hline \multicolumn{7}{|l|}{ Inflammatory cells (\%) } \\
\hline Absent & $61(6)$ & $17(45)$ & $<0.0001^{* *}$ & $67(74)$ & $11(73)$ & $1.000 * *$ \\
\hline Present & $7(33)$ & $21(55)$ & & $24(26)$ & $4(27)$ & \\
\hline \multicolumn{7}{|l|}{ Nottingham Prognostic Index } \\
\hline Good prognosis $(\leq 3.4)$ & $67(63)$ & $37(35)$ & $1.000 * *$ & $89(84)$ & $15(14)$ & $1.000 * *$ \\
\hline Moderate prognosis (3.41-5.4) & $1(2)$ & $1(2)$ & & $2(2)$ & $0(0)$ & \\
\hline
\end{tabular}

Abbreviations: ER, estrogen receptor; HPF, high-power field; H-score, histologic score; NST, no special type; PR, progesterone receptor.

${ }^{*}$ Student's $t$-test; **Kruskal-Wallis test.

In this study, we compared the clinicopathologic tumor features with risk estimations by Oncotype DX Recurrence Score and Mammostrat Prognostic Index in a series of low-grade ER-positive breast carcinomas.

\section{Materials and methods}

We selected 106 consecutive patients with early stage, ER-positive, low-grade invasive breast carcinoma who underwent Oncotype DX testing as part of their clinical care between 1 January 2006 and 31 March 2011. All hematoxylin and eosin-stained slides were reviewed to establish the diagnoses, including histologic type and grade. ${ }^{20-22}$ All invasive carcinomas were graded according to the modified combined histologic grading system. ${ }^{22}$ The number of mitoses was determined in 10 consecutive high-power $(400 \times)$ fields in the mitotically most active areas of tumors. The tumor stroma was evaluated for increased cellularity ( $v s$ a more dense, fibrous stroma) and presence of associated inflammatory cells. 
The clinicopathologic features of the tumors are summarized in Table 1. Surgical treatment consisted of lumpectomy in $72(68 \%)$ patients, whereas 34 $(32 \%)$ patients underwent mastectomy. Axillary lymph node staging was performed in all cases and consisted of sentinel lymph node biopsy in 101 $(95 \%)$ and axillary lymph node dissection in $5(5 \%)$ cases, respectively. The median number of lymph nodes per case examined was 2 (range 1-22). Axillary lymph node macro- (pN1a) and micrometastases (pN1mi) were present in four $(4 \%)$ and four $(4 \%)$ patients, respectively, whereas isolated tumor cells $[\mathrm{pNo}(\mathrm{i}+)]$ were present in five $(5 \%)$ patients. The median number of positive lymph nodes was 1 (range 1--2). ER and progesterone receptor (PR) status were evaluated by immunohistochemistry as previously described. ${ }^{19}$ In addition to categorical (positive vs negative) results, ER and PR expression were also assessed using a semi-quantitative immunohistochemical score $(\mathrm{H} \text {-score })^{23}$ taking in consideration the extent and intensity of nuclear immunoreactivity with score ranges from 0 to 300 . HER2/neu overexpression and/or gene amplification were determined by immunohistochemistry alone in $16(15 \%)$ cases, fluorescence in situ hybridization (FISH) alone in $16(15 \%)$ cases or by both methods in $74(70 \%)$ cases, as previously described. ${ }^{19}$ Twelve (11\%) cases had equivocal HER2 immunohistochemical results, none of which showed gene amplification by FISH. The Nottingham Prognostic Index, taking in consideration tumor size, histologic grade and nodal status, ${ }^{23}$ was used to estimate the risk of recurrence based on traditional clinicopathologic tumor features. Based on the Nottingham Prognostic Index, 91, 13 and 2 cases were considered to have an expected excellent $(\leq 2.4)$, good $(>2.4$ but $\leq 3.4)$ and moderate prognosis (>3.4), respectively. As both patients in the excellent and good prognostic groups were reported to have excellent 10-year survival (96 $\pm 2 \%$ and $93 \pm 2 \%$, respectively), ${ }^{24}$ these groups were combined for statistical analysis. At a mean
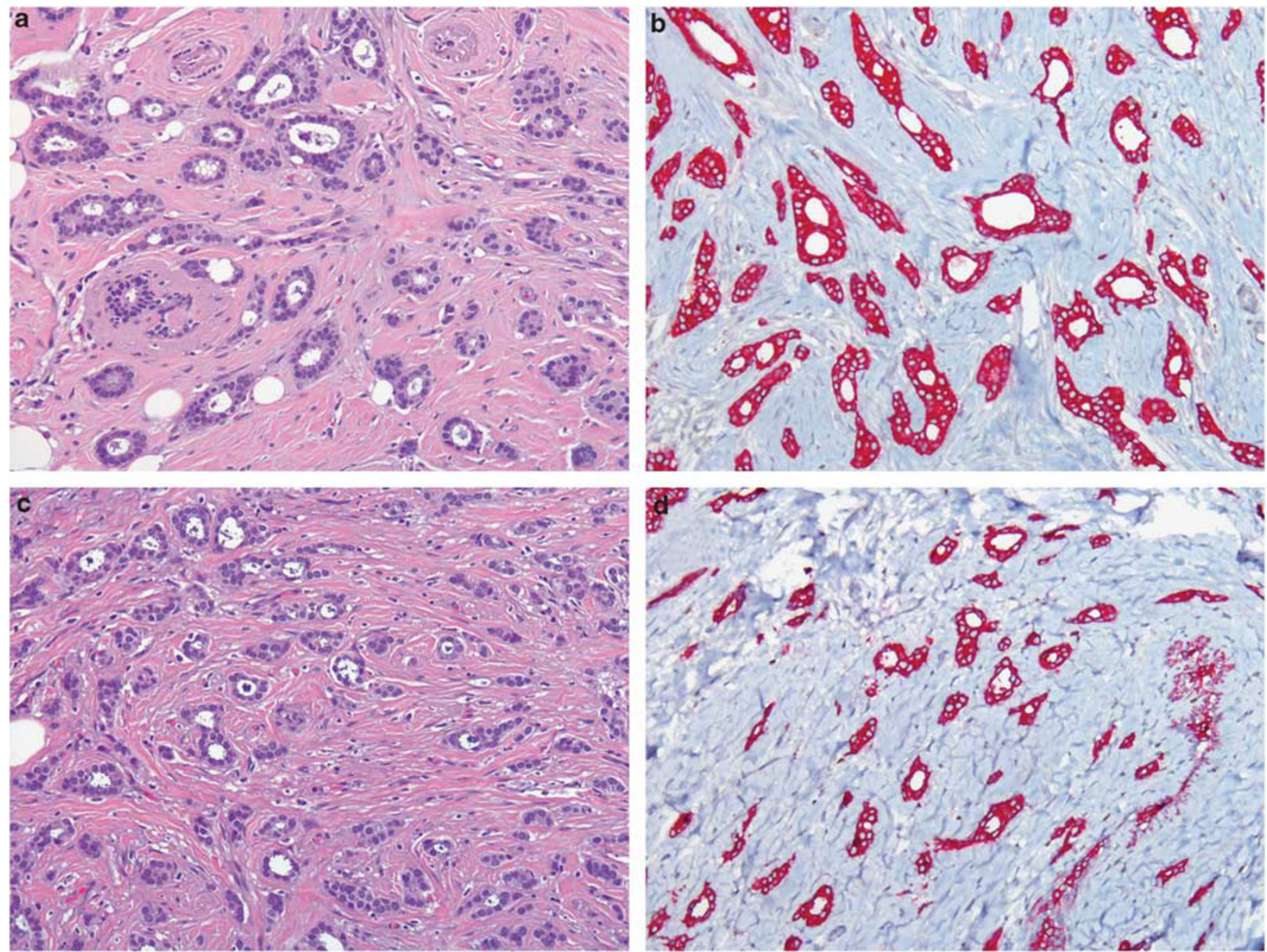

Figure 1 (a-d) Examples of low-grade invasive ductal carcinomas with low-risk estimations by both Oncotype DX Recurrence Score and Mammostrat. Note that the tumor stroma is fibrotic and lack significant proliferation as determined by Ki-67 immunohistochemistry (b, d). (e-h) Examples of low-grade invasive ductal carcinomas with intermediate-risk estimations by Oncotype DX Recurrence Score but low-risk estimations by Mammostrat. Note that the tumor stroma is cellular with spindled stromal and inflammatory cells. Ki-67 immunohistochemical stains show significant proliferative activity within the tumor stroma, but not in the cancer cells. (a, c, e, g) Hematoxylin and eosin stain; (b, d, f, h) double immunohistochemical stains for cytokeratin (red) and Ki-67 (brown). 

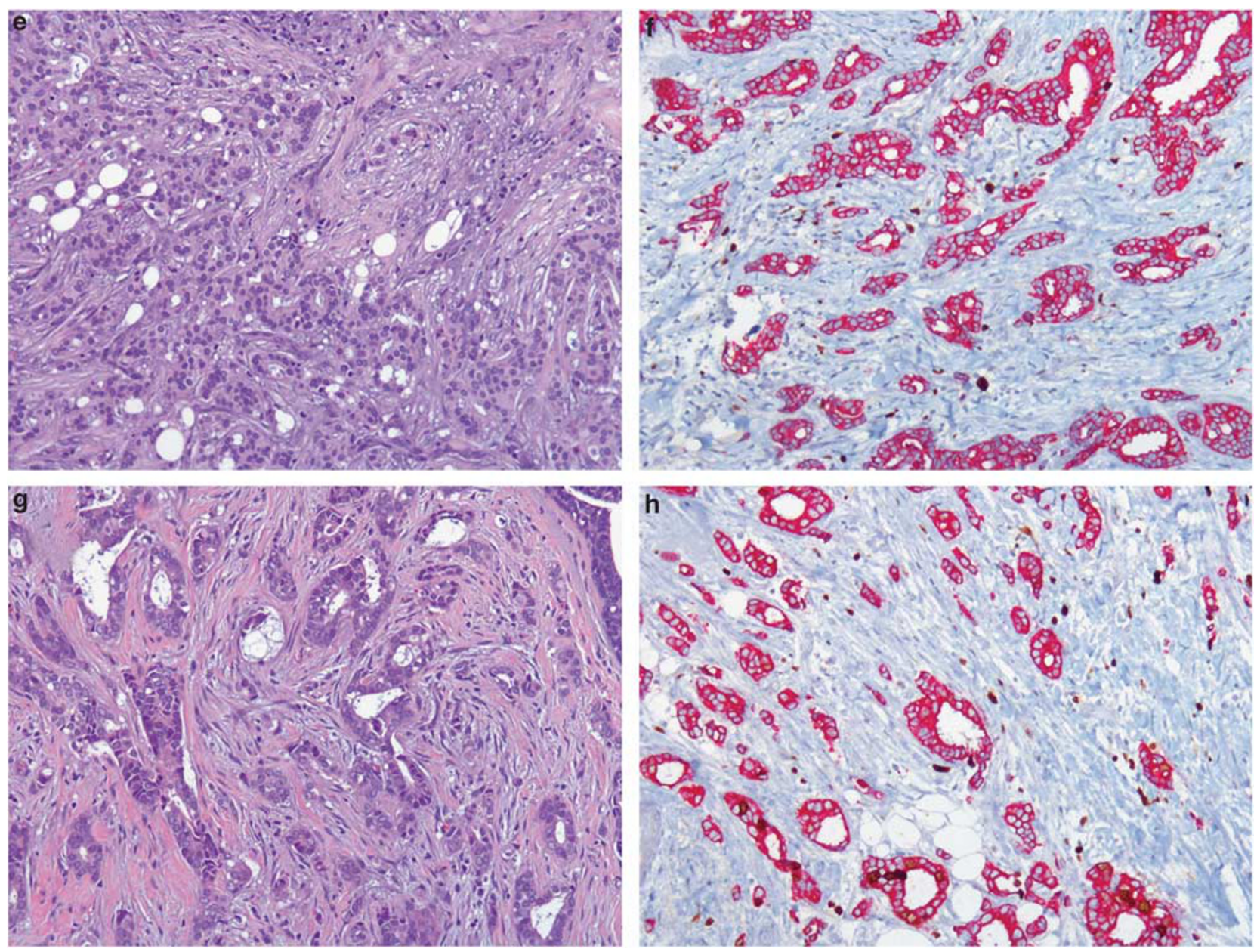

Figure 1 Continued.

follow-up time of 54.3 (range 20.1-83.2) months, no tumor recurrence was observed in any of the patients. Study protocols were approved by the University of South Florida Institutional Review Board.

The tumor tissue block used for Oncotype DX testing was used for immunohistochemical and Mammostrat assays in each case. The Mammostrat assays were performed and analyzed by Clarient as previously described. ${ }^{10-12}$ A double immunohistochemical stain for pancytokeratin and Ki-67 was performed in each case to assess cell proliferation in cancer vs stromal/inflammatory cells, as previously described. ${ }^{19}$ The areas of cancers showing the highest numbers of Ki-67-positive cancer and stromal/inflammatory cells were identified at lowpower magnification. Three representative images of tumor and/or tumor stroma showing the highest numbers of Ki-67-positive cells were obtained using a digital camera. Each image taken at a magnification of $200 \times$ represented an area measuring $0.6554 \mathrm{~mm}^{2}$. Ki-67-positive stromal/inflammatory (pancytokeratin-negative) and cancer (pancytokeratin-positive) cells were counted manually and the mean values of the counts were obtained. As samples used for Oncotype DX testing do not undergo microdissection of tumor cells from stromal/inflammatory cells, results were expressed as the number of Ki-67-positive tumor and stromal/ inflammatory cells per $\mathrm{mm}^{2}$ of tissue.

The clinicopathologic features of carcinomas with Recurrence Score <18 (low risk) vs Recurrence Score $\geq 18$ (intermediate/high risk), and Mammostrat Prognostic Index $\leq 0$ (low risk) vs Prognostic Index $>0$ (moderate/high risk) were compared using the Mann-Whitney test, Student's $t$-test and $\chi^{2}$ test, when appropriate. The rate of agreement between Oncotype DX and Mammostrat risk stratifications was assessed using kappa statistics. Statistical significance was determined if the two-sided $P$ value of a test was $<0.05$. Computations were performed using the Graphpad Prism (Version 5, GraphPad Software, San Diego, CA, USA) software.

\section{Results}

Among the 106 cases, based on Oncotype DX Recurrence Score and Mammostrat Prognostic Index 68, 38 and 0, and 91, 14 and 1 cases showed low-, intermediate- and high-risk estimates of distant 

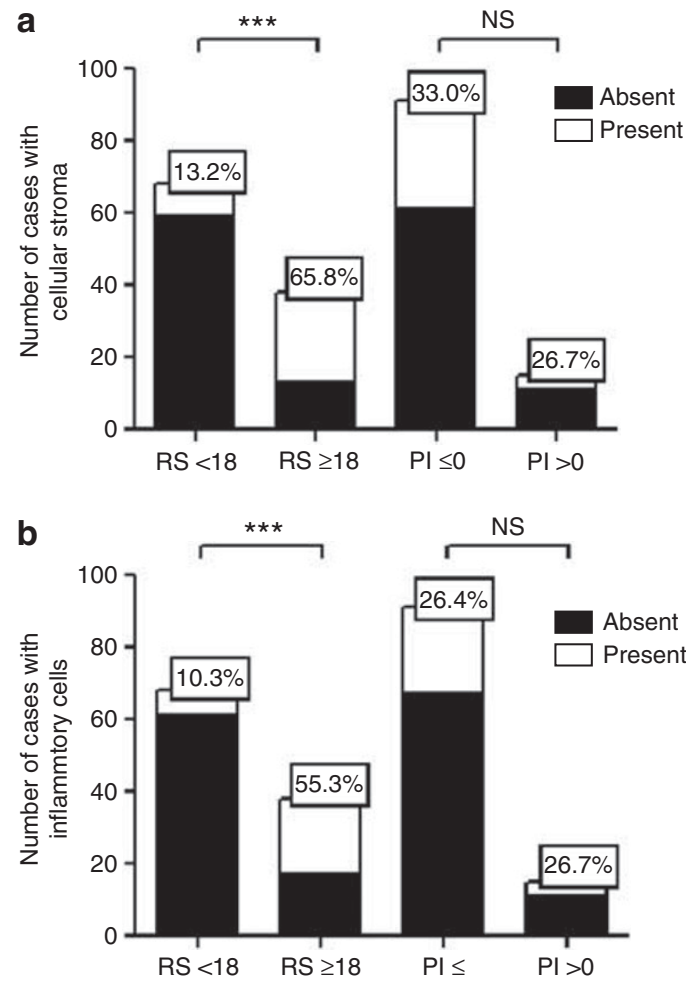

Figure 2 Comparison of the number of cases associated with cellular tumor stroma (a) and inflammatory cells (b) in breast carcinomas classified as low vs intermediate/high risk for distant recurrence by Oncotype DX Recurrence Score (RS) and Mammostrat Prognostic Index (PI), respectively. ${ }^{* *} P<0.0001$; NS, not significant, Chi-square test.

recurrence, respectively. The Recurrence Score and Prognostic Index agreed with the risk estimations based on clinicopathologic tumor features (Nottingham Prognostic Index) in $68(65.2 \%)$ and 89 (84.0\%) of 106 cases, respectively. The correlation of clinicopathologic tumor features with Recurrence Score and Prognostic Index is summarized in Table 2. Tumors showing intermediate-/high-risk estimation by the Recurrence Score showed significantly lower PR expression, increased stromal cellularity and presence of inflammatory cells intimately associated with the tumor cells (Figures 1 and 2). In contrast, we found no difference in PR expression, stromal cellularity or the presence of inflammatory cells between cases showing low vs intermediate/high recurrence risk estimation by the Prognostic Index.

Assessment of the concurrence between the Recurrence Score and the Prognostic Index to predict low vs intermediate/high risk of tumor recurrence showed a kappa value of 0.0541 . When the comparison was made according to the three risk categories in both tests, the kappa value was less than that expected by chance. There was no statistically significant correlation between Recurrence Score and Prognostic Index values ( $r=-0.0737, P=0.4527$, Spearman test).
We found no statistically significant difference in the number of mitoses per 10 high-power fields present in cancer cells between tumors classified as low vs intermediate/high risk by either the Recurrence Score or the Prognostic Index (Table 2 and Figure 3a). Similarly, there was no difference in the number of Ki-67-positive cancer cells per $\mathrm{mm}^{2}$ of tissue between tumors classified as low vs intermediate/high risk by either the Recurrence Score or the Prognostic Index (Figure 3b). In contrast, tumors showing intermediate/high Recurrence Score had significantly increased numbers of Ki-67-positive stromal/inflammatory cells per $\mathrm{mm}^{2}$ of tumor tissue compared with tumors showing low Recurrence Score (Figure 3c); no such difference was seen between tumors classified as low vs intermediate/ high risk by the Prognostic Index. The ratio of Ki-67positive stromal/inflammatory vs tumor cells per $\mathrm{mm}^{2}$ of tumor tissue was also significantly higher in cancers showing intermediate/high vs low Recurrence Score; no such difference was found between tumors showing intermediate/high vs low Prognostic Index (Figure 3d). The ratio of Ki-67-positive stromal/inflammatory $v s$ tumor cells $>1$ had an area under the curve of $0.8929(P<0.0001)$ and $0.5026 \quad(P=0.9823)$ to predict intermediate/ high recurrence risk based on the Recurrence Score and the Prognostic Index, respectively (Figures 3e and f).

Comparison of 'concordant' (low- vs intermediate-/high-risk estimations by both tests, $n=64$ ) with 'discordant' (low by one but intermediate-/high-risk estimation by the other test, $n=42$ ) cases showed no significant difference between 'concordant' and 'discordant' cases according to the number of tumor cell mitoses per 10 high-power fields or the number of Ki-67-positive tumor cells by $\mathrm{mm}^{2}$ of tissue (Figures 4a and b). In contrast, the number of Ki67-positive stromal/inflammatory cells per $\mathrm{mm}^{2}$ of tissue and the ratio of Ki-67-positive stromal/ inflammatory vs tumor cells was significantly higher in tumors classified as intermediate/high risk by the Recurrence Score but low risk by the Prognostic Index $(n=33)$ compared with cases classified as low risk by both assays ( $n=58$; Figures $4 \mathrm{c}$ and $d)$.

\section{Discussion}

The main finding of this study is that in low-grade, ER-positive breast carcinomas, molecular prognostic/predictive assays examining tumor cells specifically to estimate likely biologic behavior appear to be more in line with what would be expected based on clinicopathologic tumor features and historical outcome data compared with assays also including molecular signatures from mitotically active tumor stroma and/or intimately associated inflammatory cells.

Traditionally, treatment decisions for patients with breast cancer are based on clinicopathologic 
a

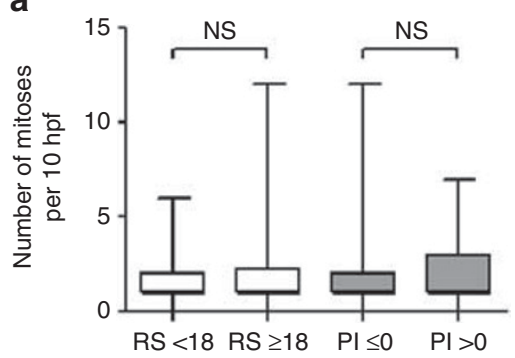

C

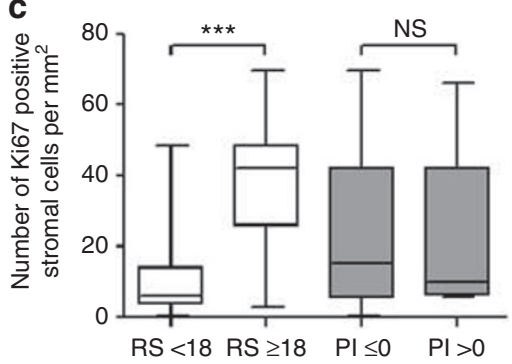

e

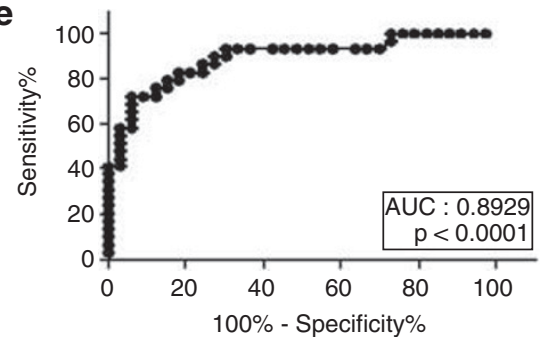

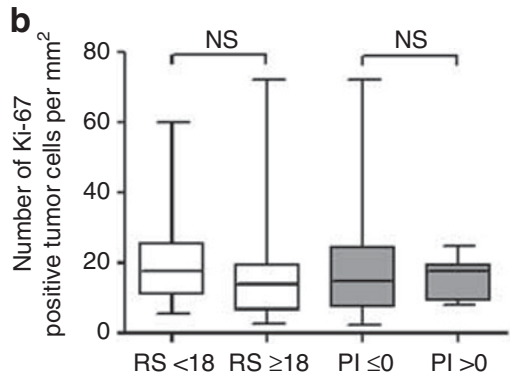

d
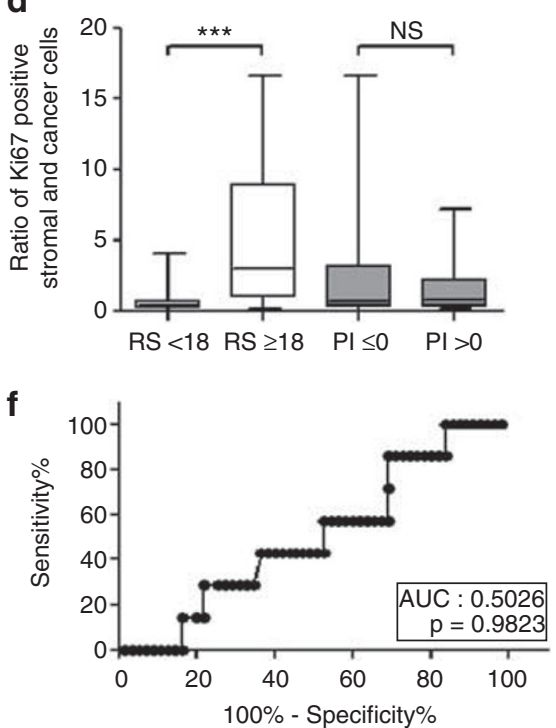

Figure 3 Comparison of the number of mitoses in cancer cells per 10 high-power fields (a), the number of Ki-67-positive cancer cells (b), number of Ki-67-positive stromal/inflammatory cells (c) and the ratio of Ki-67-positive stromal and cancer cells (d) in low-grade invasive breast carcinomas with low- vs intermediate-/high-risk estimations by Oncotype DX Recurrence Score (RS) and Mammostrat Prognostic Index (PI). (e) Receiver operator curve (ROC) for the ratio of Ki-67-positive stromal and cancer cells to predict an intermediate/high Oncotype DX Recurrence Score. (f) Receiver operator curve (ROC) for the ratio of Ki67-positive stromal and cancer cells to predict an intermediate-/high-Mammostrat risk index. ${ }^{* *} P<0.0001$; NS, not significant, Student's $t$-test.

tumor features and patient characteristics. One of the most established and validated histopathologic prognostic feature is tumor grade, as determined by the modified combined histologic (Nottingham) grading system. ${ }^{22,23,25}$ The prognostic value of the Nottingham grade has been established and validated in multiple large independent studies ${ }^{26-30}$ and incorporated into prognostic algorithms, such as the Nottingham Prognostic Index ${ }^{23,24,31}$ and clinical guidelines. ${ }^{32}$ Recent gene expression profiling studies have also shown that tumors of different histological grades show distinct molecular profiles suggesting that histologic grade is indeed an accurate morphologic reflection of the molecular makeup of breast cancers ${ }^{7,26}$ and emphasized its relevance in breast cancer biology and behavior. ${ }^{33,34} \mathrm{~A}$ compelling body of evidence suggests that histologic grade can accurately predict tumor behavior, particularly in early stage, small tumors, such as those included in this study. ${ }^{25,29,35}$ Specifically, patients with breast cancers in the excellent and good Nottingham Prognostic Index groups (104 of 106 cases in this study) were reported to have excellent ( $96 \pm 2$ and $93 \pm 2 \%$, respectively) 10 -year survival rates. ${ }^{24}$ Several other large studies have also shown that patients with early stage, lowgrade invasive breast carcinoma have an excellent outcome with over $95 \%$ survival. ${ }^{35-37}$ Indeed, we did not observe any recurrence in our series of lowgrade, early stage breast cancers, although the mean follow-up time was relatively short (54.3 months).

On the other hand, the gene expression profiling studies have also highlighted the perceived subjectivity associated with histologic grading ${ }^{3,14}$ and some authors suggested that molecular tests perform better and may replace traditional histopathology as the 'gold standard' for prognostication and prediction of response to therapy. ${ }^{38}$ However, in order to critically evaluate their role in breast cancer management, we must understand the limitations of the available molecular prognostic/predictive tests, ${ }^{2}$ apart from the recognized subjectivity of the biostatistical approaches they employ. ${ }^{26}$ Recent studies comparing various algorithms for molecular classification showed less than optimal agreement, comparing unfavorably with agreement 
a
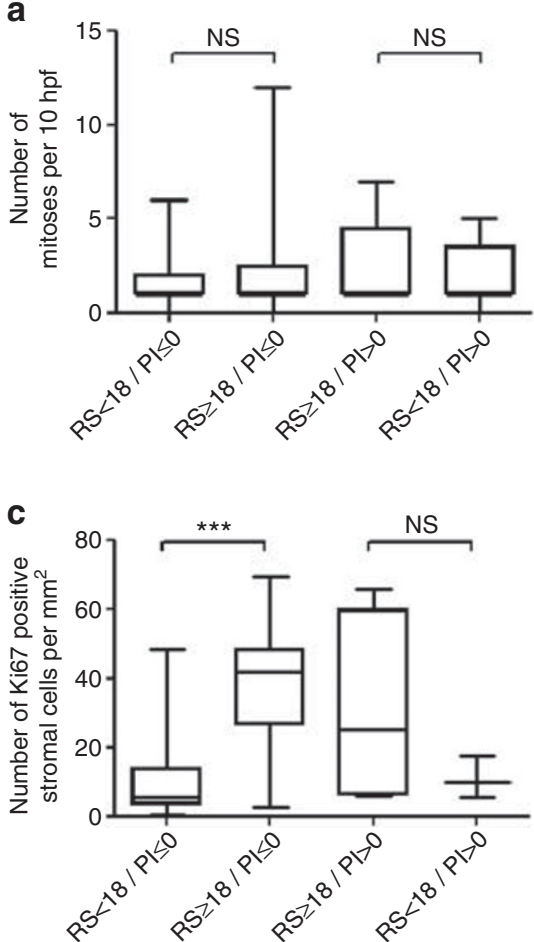
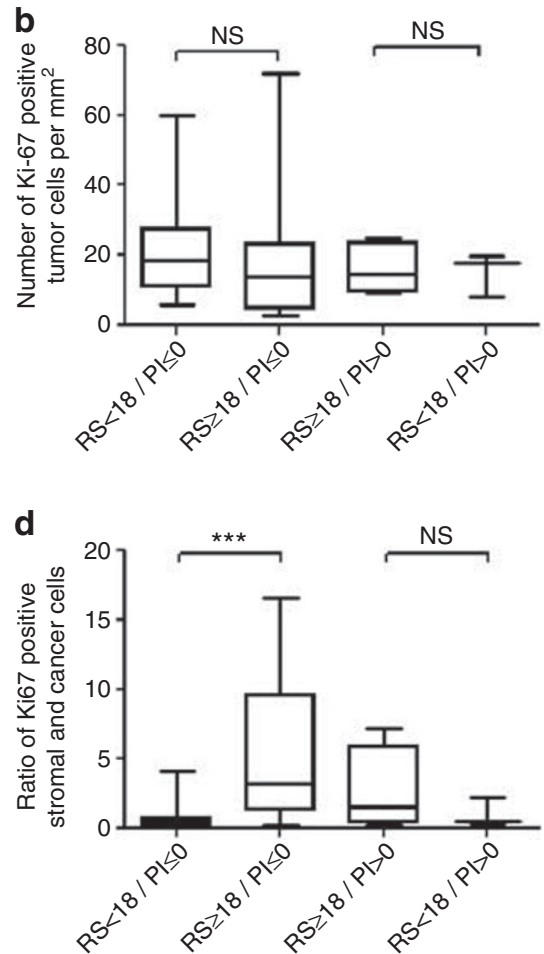

Figure 4 Comparison of the number of mitoses in cancer cells per 10 high-power fields (a), the number of Ki-67-positive cancer cells (b), number of Ki-67-positive stromal/inflammatory cells (c) and the ratio of Ki-67-positive stromal and cancer cells (d) in low-grade invasive breast carcinomas with concordant vs discrepant (low- vs intermediate-/high-) risk estimations by Oncotype DX Recurrence Score (RS) and Mammostrat Prognostic Index (PI). (RS $<18 / \mathrm{PI} \leq 0, n=58 ; \mathrm{RS} \geq 18 / \mathrm{PI} \leq 0, n=33 ; \mathrm{RS} \geq 18 / \mathrm{PI}>0, n=5$ and RS $<18 / \mathrm{PI}>0, n=10$ ). NS, not significant; ${ }^{* * *} P<0.0001$, Student's $t$-test.

rates for grading between experienced breast pathologists. ${ }^{26,35,39}$ Based on our results in this highly selected group of low-grade, ER-positive, early stage breast cancers, the agreement between the Oncotype DX Recurrence Score and the Mammostrat Prognostic Index is poor, worse than agreement rates between pathologists regarding tumor grading, $26,35,39$ and might be even poorer if cancers of all grades had been included.

Several reasons may exist accounting for the discordance between the assays examined. Of note, in contrast to Oncotype DX, Mammostrat does not incorporate hormone receptor and HER2 status, or measures of cell proliferation into its risk-stratification algorithm, resulting in an estimate based on tumors features different from those routinely assessed and reported by pathologists. ${ }^{14}$ It was thus previously suggested that unlike Oncotype DX, Mammostrat appears to identify biological drivers of disease relapse that actually complement conventional pathological and biological markers (ie, ER, PR, HER2, Ki-67) and its results could be interpreted in conjunction with the conventional clinicopathologic features of breast cancers. ${ }^{14}$

It is also important to note that, apart from other methodological differences (RT-PCR vs IHC), Mammostrat specifically examines tumors cells, whereas cDNA from both tumor and associated stromal/ inflammatory cells is included in the Oncotype DX assay and not controlled for when the Recurrence
Score is calculated. As such, Oncotype DX suffers from the inherent limitations present when a portion of tissue is used that contains both invasive cancer and associated stromal/inflammatory cells. Regarding the possible effect of inflammation on the Recurrence Score, one previous study suggested that in some cases a high Recurrence Score may be more related to peritumoral inflammatory response rather than the tumor cells themselves. ${ }^{40}$ Our recent data indicate that in low-grade ER-positive breast cancers, a mitotically active tumor stroma and/or inflammatory cells can indeed contribute to increased risk estimations by the Recurrence Score compared with those expected based on clinicopathologic features and reported outcome data. ${ }^{19}$ Recent meta-analyses of microarray-based expression profiling studies have also demonstrated that the apparent prognostic impact of the molecular signatures investigated, including the Recurrence Score, mainly stems from the proliferation-related genes, ${ }^{41,42}$ either expressed by tumor or associated stromal/inflammatory cells.

Our current results suggest that in contrast to the Recurrence Score, risk estimations by Mammostrat are independent of stromal/inflammatory cell proliferation and appear to be more in line with what would be expected based on clinicopathologic data and the historically excellent outcome in early stage, low-grade, ER-positive breast cancers. This is further highlighted by the finding that the only 
difference between 'concordant' and 'discordant' cases as estimated by the two assays was increased stromal/inflammatory cell proliferation, but not features of the cancer cells themselves, in tumors with intermediate/high Recurrence Score. Indeed, this is not surprising given the dependence of the Recurrence Score primarily on cell proliferation, markers for which are not included in Mammostrat.

It is well known that tumor-stroma interactions have a significant role in tumor development and progression, and alterations in the stromal microenvironment, such as enhanced vasculature, modified extracellular matrix composition, inflammatory cells and unbalanced protease activity, are essential regulatory factors of tumor growth and invasion. ${ }^{43}$ However, these effects are mainly thought to be mediated by the expression of cytokines and growth factors by the cancer associated fibroblasts/inflammatory cells and it is unlikely that the proliferative activity of these cells per se (as measured by the Oncotype DX assay) has a significant role in these processes.

Although it is clear that the best method to determine which assay is more accurate in predicting recurrence would be actual long-term outcome data, our relatively short-term follow-up (despite the lack of tumor recurrence in any of the cases so far), does not allow us to address this issue at the present time. Nevertheless, based on reported outcome data in small, low-grade, node-negative, ER-positive breast cancers, ${ }^{35,36}$ we expect an excellent outcome in the cases included in this study.

In summary, our study suggests that the presence of a mitotically active, cellular tumor stroma and/or inflammatory cells associated with the tumor in low-grade invasive breast carcinomas may contribute to Oncotype DX Recurrence Score results suggesting an apparently increased risk of recurrence. As the Mammostrat assay examines only tumor cells, this potential confounder/bias does not seem to have a role in risk estimations by this latter test. Given the inherent characteristics of the assay, clinicians and pathologists should be alert to the possibility that the Oncotype DX Recurrence Score may not be an accurate representation of the true cancer biology in a subgroup of low-grade breast cancers associated with a cellular tumor stroma and/ or admixed inflammatory cells. Careful pathologic assessment, correlation with histopathologic features and utilization of alternative molecular tests examining tumor cells specifically in such cases may help in determining appropriate patient management.

\section{Acknowledgements}

The Mammostrat assays were performed by Clarient free of charge for this study. This work has been presented in part at the San Antonio Breast Cancer Symposium, San Antonio, TX, USA, 6-10 December 2011.

\section{Disclosure/conflict of interest}

Drs Acs, Loftus and Laronga are on the Speakers' Bureau for Genomic Health. Dr Acs is on the Speakers' Bureau for Clarient. The remaining author declares no conflict of interest.

\section{References}

1 Weigelt B, Reis-Filho JS. Histological and molecular types of breast cancer: is there a unifying taxonomy? Nat Rev Clin Oncol 2009;6:718-730.

2 Weigelt B, Baehner FL, Reis-Filho JS. The contribution of gene expression profiling to breast cancer classification, prognostication and prediction: a retrospective of the last decade. J Pathol 2010;220:263-280.

3 Paik S, Shak S, Tang G, et al. A multigene assay to predict recurrence of tamoxifen-treated, node-negative breast cancer. N Engl J Med 2004;351:2817-2826.

4 Perou CM, Sorlie T, Eisen MB, et al. Molecular portraits of human breast tumours. Nature 2000;406: 747-752.

5 Sorlie T, Perou CM, Tibshirani R, et al. Gene expression patterns of breast carcinomas distinguish tumor subclasses with clinical implications. Proc Natl Acad Sci USA 2001;98:10869-10874.

6 van de Vijver MJ, He YD, Van't Veer LJ, et al. A gene-expression signature as a predictor of survival in breast cancer. N Engl J Med 2002;347:1999-2009.

7 Sotiriou C, Wirapati P, Loi S, et al. Gene expression profiling in breast cancer: understanding the molecular basis of histologic grade to improve prognosis. J Natl Cancer Inst 2006;98:262-272.

8 Wang Y, Klijn JG, Zhang Y, et al. Gene-expression profiles to predict distant metastasis of lymphnode-negative primary breast cancer. Lancet 2005;365: 671-679.

9 Potti A, Dressman HK, Bild A, et al. Genomic signatures to guide the use of chemotherapeutics. Nat Med 2006;12:1294-1300.

10 Ring BZ, Seitz RS, Beck R, et al. Novel prognostic immunohistochemical biomarker panel for estrogen receptor-positive breast cancer. J Clin Oncol 2006;24: 3039-3047.

11 Ross DT, Kim CY, Tang G, et al. Chemosensitivity and stratification by a five monoclonal antibody immunohistochemistry test in the NSABP B14 and B20 trials. Clin Cancer Res 2008;14:6602-6609.

12 Bartlett JM, Thomas J, Ross DT, et al. Mammostrat as a tool to stratify breast cancer patients at risk of recurrence during endocrine therapy. Breast Cancer Res 2010;12:R47.

13 Esteva FJ, Sahin AA, Cristofanilli M, et al. Prognostic role of a multigene reverse transcriptase-PCR assay in patients with node-negative breast cancer not receiving adjuvant systemic therapy. Clin Cancer Res 2005;11:3315-3319.

14 Paik S, Tang G, Shak S, et al. Gene expression and benefit of chemotherapy in women with nodenegative, estrogen receptor-positive breast cancer. J Clin Oncol 2006;24:3726-3734.

15 Carlson RW, Allred DC, Anderson BO, et al. Breast cancer. Clinical practice guidelines in oncology. J Natl Compr Canc Netw 2009;7:122-192. 
16 Harris L, Fritsche H, Mennel R, et al. American Society of Clinical Oncology 2007 update of recommendations for the use of tumor markers in breast cancer. J Clin Oncol 2007;25:5287-5312.

17 Allison KH, Kandalaft PL, Sitlani CM, et al. Routine pathologic parameters can predict Oncotype DX(TM) recurrence scores in subsets of ER positive patients: who does not always need testing? Breast Cancer Res Treat 2011;131:413-424.

18 Baehner F, Quale C, Pomeroy C, et al. Biopsy cavities in breast cancer specimens: their impact on quantitative RT-PCR gene expression profiles and recurrence risk assessment [abstract]. Mod Pathol 2008;22: 28A-29AA.

19 Acs G, Esposito NN, Kiluk J, et al. A mitotically active, cellular tumor stroma and/or inflammatory cells associated with tumor cells may contribute to intermediate or high Oncotype DX Recurrence Scores in low-grade invasive breast carcinomas. Mod Pathol 2012;25:556-566.

20 Pinder SE, Elston CW, Ellis IO. Invasive carcinoma usual histologic types, In: Elston CW, Ellis IO(eds). The Breast, 3 edn. Churchill Livingstone: Edinburgh; 1998, pp 283-337.

21 Page DL, Anderson TJ, Sakamoto G. Infiltrating carcinoma: major histologic types, In: Page DL, Anderson TJ (eds). Diagnostic Histopathology of the Breast. WB Saunders: London; 1987, pp 193-235.

22 Elston CW, Ellis IO. Assessment of histologic grade, In: Elston CW, Ellis IO (eds). The Breast, 3 edn. Churchill Livingstone:: Edinburgh; 1998, pp 365-384.

23 Elston CW, Ellis IO, Goulding $\mathrm{H}$, et al. Role of pathology in the prognosis and management of breast cancer, In: Elston CW, Ellis IO (eds). The Breast. Churchill Livingstone: Edinburgh; 1998, pp 385-433.

24 Blamey RW, Ellis IO, Pinder SE, et al. Survival of invasive breast cancer according to the Nottingham Prognostic Index in cases diagnosed in 1990-1999. Eur J Cancer 2007;43:1548-1555.

25 Elston CW, Ellis IO. Pathological prognostic factors in breast cancer. I. The value of histological grade in breast cancer: experience from a large study with long-term follow-up. Histopathology 2002;41:154-161.

26 Rakha EA, Reis-Filho JS, Baehner F, et al. Breast cancer prognostic classification in the molecular era: the role of histological grade. Breast Cancer Res 2010;12:207.

27 Lundin J, Lundin M, Holli K, et al. Omission of histologic grading from clinical decision making may result in overuse of adjuvant therapies in breast cancer: results from a nationwide study. J Clin Oncol 2001;19:28-36.

28 Simpson JF, Gray R, Dressler LG, et al. Prognostic value of histologic grade and proliferative activity in axillary node-positive breast cancer: results from the Eastern
Cooperative Oncology Group Companion Study, EST 4189. J Clin Oncol 2000;18:2059-2069.

29 Frkovic-Grazio S, Bracko M. Long term prognostic value of Nottingham histological grade and its components in early (pT1N0M0) breast carcinoma. J Clin Pathol 2002;55:88-92.

30 Mirza AN, Mirza NQ, Vlastos G, et al. Prognostic factors in node-negative breast cancer: a review of studies with sample size more than 200 and follow-up more than 5 years. Ann Surg 2002;235:10-26.

31 Todd JH, Dowle C, Williams MR, et al. Confirmation of a prognostic index in primary breast cancer. Br J Cancer 1987;56:489-492.

32 Goldhirsch A, Ingle JN, Gelber RD, et al. Thresholds for therapies: highlights of the St Gallen International Expert Consensus on the primary therapy of early breast cancer 2009. Ann Oncol 2009;20:1319-1329.

$33 \mathrm{Yu} \mathrm{K}$, Lee CH, Tan PH, et al. A molecular signature of the Nottingham prognostic index in breast cancer. Cancer Res 2004;64:2962-2968.

$34 \mathrm{Lu} \mathrm{X}$, Lu X, Wang ZC, et al. Predicting features of breast cancer with gene expression patterns. Breast Cancer Res Treat 2008;108:191-201.

35 Rakha EA, El-Sayed ME, Lee AH, et al. Prognostic significance of Nottingham histologic grade in invasive breast carcinoma. J Clin Oncol 2008;26:3153-3158.

36 Henson DE, Ries L, Freedman LS, et al. Relationship among outcome, stage of disease, and histologic grade for 22,616 cases of breast cancer. The basis for a prognostic index. Cancer 1991;68:2142-2149.

37 Rakha EA, Lee AH, Evans AJ, et al. Tubular carcinoma of the breast: further evidence to support its excellent prognosis. J Clin Oncol 2010;28:99-104.

38 Peppercorn J, Perou CM, Carey LA. Molecular subtypes in breast cancer evaluation and management: divide and conquer. Cancer Invest 2008;26:1-10.

39 Robbins $\mathrm{P}$, Pinder S, de KN, et al. Histological grading of breast carcinomas: a study of interobserver agreement. Hum Pathol 1995;26:873-879.

40 Grimes M, Coad J, Oliviero B, et al. Comparison of Oncotype DX Recurrence Score and standard immunohistochemical prognostic markers [abstract]. Mod Pathol 2007;20:33A.

41 Wirapati P, Sotiriou C, Kunkel S, et al. Meta-analysis of gene expression profiles in breast cancer: toward a unified understanding of breast cancer subtyping and prognosis signatures. Breast Cancer Res 2008;10:R65.

42 Desmedt C, Haibe-Kains B, Wirapati P, et al. Biological processes associated with breast cancer clinical outcome depend on the molecular subtypes. Clin Cancer Res 2008;14:5158-5165.

43 Ingber DE. Cancer as a disease of epithelial-mesenchymal interactions and extracellular matrix regulation. Differentiation 2002;70:547-560. 